\title{
Energy Analysis of a Green Building using Equest Software
}

\author{
G. L. Sathyamoorthy, T. Santhosh
}

\begin{abstract}
At present understading the behaviour of buildings with respect to energy useage becomes a difficult task due to the various factors affecting the energy use. Neverthless, the perpetual advent of software have provided plenty of oppetunities in forecating energy performance of a building,once it is put for usage. In the present study an energy simulating tool is used to model the thermal, ventilation and various energy intaking processes in a building to forecast its energy performance. In order precisely calculate the energy usages in building the tool consider the outside claimate of the building warmth resources within the building and the use of construction materials. This building energy imitating technique is argubly proved as an influential practice for observing energy routine of building,estimating architectural design, decide upon appropiate structural resources and system required as well.Using this tool complex issues with respect to buildings could be scrutinized and their performances also be appraised.
\end{abstract}

Key Words:-eQuest, Building Energy Investigation Tool(BEIT), HAVC, Climatic factors,Simulation.

\section{INTRODUCTION}

Energy investigation tools are essential for engineers and builders for providing useful forms in their buildings. Buildings Energy Investigation Tools (BEIT) studies the active energy requirement of a building using computer models and imitation techniques. Also such tools helps for the inclusive use of several examinations and creation of images during the design development practice i.e from the theoretical and graphical phases to the thorough requirement of building works and systems. Building Energy Investigation Tool (BEIT) is doing an important role not only in building design, but also helps in planning, commissioning and assessment of buildings. It assists engineers to judge against the various design options and support them to adopt cost effective energy proficient design. BEIT also help the construction managers and designers to recognize energy saving potentials and to appraise the energy performance as well in the building. At present many BEITs are available focusing simplified quick energy analysis only (i.e annual energy use of buildings) and some may analyses the hour-by-hour energy analysis of buildings. In a building any BEITs could be conveniently used for assessing its energy performance and the only pre requisite required is the calibration of the BEIT for its accuracy and usability in energy simulation. In the calibration process the data acquired by the BEIT is compared with field measured data and refrained until its results are closely matched the measured data. In the present study a two-storey residence is used to predict the data using
eQuest BEIT. Along with the eQuest BEIT results, the technique of detailing own wall and roof creation is also included for better analysis of the data.

The current work has been separated into four segments namely (1) Portrayal of structure, (2)training of input data in a directly usable format for energy investigation and analysis, (3)Generating the imitation model in eQUEST Building Energy Investigation Tool, (4) Running the BEIT and examination of results. In order to demonstrate the eQUEST software, a small building structure was analyzed by using the eQUEST Building Energy Investigation Tool and the results were analyzed as well.

\section{GENERAL INSTRUCTIONS}

Since it is customary to give information in an organised understandable format so as to help in the simulation process, an input sheet was prepared converting all the available raw data into an usable format. The general portrayal and place condition of the project are as deatied below.

1. Project name : New Contruction

2. Location: Madras (Chennai), India.

3. Indian Society of Heating, Refrigerating \& Airconditioning Engineers (ISHRAE) Chennai chapter is employed in the investigation

4. The Facing of the building is North and

5. Heating, Ventilation, and Air Conditioning (HVAC) arrangement is provided in the building

\section{A. HVAC Systems}

In HVAC arrangement the details like type of system used for cooling and heating, purposes and its efficiencies are included including the set point temperatures maintained inside the zones.All the specific zones where the set point temperature are different need to be mentioned specifically for the effective simulation of the dats.In the proposed building the following HAVC features are used

1. A simple package single zone air conditioning system was used to suffice the cooling necessities.

2. No heating is necessary, since the building is located in Chennai

3. The coefficient of performance (COP) of the cooling structure adopted was 3.0.

4. Cooling and Heating temperature set point maintained was $75 \mathrm{oF}$ and $70 \mathrm{oF}$ respectively

5. The fan speed fan and its motor efficiency were taken as 0.9 in the proposed building.
Revised Manuscript Received on 14 August, 2019.

G.L.Sathyamoorthy-Faculty,Civil Engineering Dept,Kumaraguru College of Technology,Coimbatore, Tamilnadu, India.

Er.T.Santhosh - Civil Engineering Student,Kumaraguru College of Technology,Coimbatore, Tamilnadu, India. 


\section{METHOD\& PROCEDURE}

\section{A. Creating the simulation model in equest:}

Building Energy Investigation Tool investigation could be created by following the steps as shown below.

1. Select appropriate wizard \& Enter general information.

2. Define building shape \& construction with Uvalue.

3. Select the building interiors \&define the doors and windows.

4. Select the Window shades and skylights.

5. Define area allocation \& lighting and equipment loads.

6. Define schedule of operation of equipments.

7. Define HVAC equipment type \& Specify Set points for cooling/heating.

8. State competency of cooling system \& planned program of HVAC system.

9. Detail other particulars \& Compile the model for output \& error checking.

10. After model compilation, check the 3-D geometry.

\section{B. Running the Simulation and Analysis of Results}

outcomes of model were accumulated and exhibited in two key groups:

1. Synopsis of outcome: The monthly variation of energy consumption including break up of monthly energy consumption, peak demand and service bills (if tariff of electricity and gas are specified). HVAC system competency and other related macro level outcomes.

2. Comprehensive simulation outcome: The comprehensive stock up of results, which could provide features up to hourly level. This data is necessary for performing the micro level examinations, when expected results are obtained or poor presentation of building cover or need of improvement HVAC system as well.

3. From the result analysis it is understood that almost in all the cases, the results were sufficient enough and helped to have an idea on how the proposed building is performing in the given context.

Quick check: Could be performed by dividing theenire yearly energy utilization by the complete carpet area of building. If the result of the above calculation falls well within the limits of $10 \mathrm{kWh} / \mathrm{sqft}$ to $25 \mathrm{kWh} / \mathrm{sqft}$, it could be widely accepted. Also from the above rannge of results, it evident that better the building specification envelope, lighting, HVAC, the lesser is the number.

\section{Viewing HVAC System Size Results:}

1. Air-side of HVAC system is selected.

2. 'Summary' could be selected to view system dimension and outcome for every zone, floor and total at the end.

3. At the bottom of the summary the total 'tonnage' of cooling system will be presented. The total hours outer to throttling range designate 'unmet hours' duration for which internal situation in space was outside of the specific choice.

Quick check: the intended competencey for 'cool' in sqft/ ton unit must be in the range of $150 \mathrm{sqft} /$ ton to $300 \mathrm{sqft} /$ ton. superior the number, better for the building,but standards superior than $350 \mathrm{sqft} /$ ton are not easy to attain and need meticulous inspection of the investigation. There are various margins of 'Schematic Wizard', and it is not possible to incorporat through schematic wizard for a few alterations/ conditions as well. It is also feasible to give a huge mixture of terms related to building cover/ HVAC/ lighting/ practice in 'Design Development Wizard' and in the 'detailed edit mode'.Neverthless it is imperative to be aware of the essential operation of Schematic Wizard before leaping into advanced stages and further it is essential to recognize the 'Cause-Effect' relationship during special potential deviations as well.

\section{D.Energy Analysis of the Proposed Building}

The proposed building is analysed using the eQuest software as shown above. After simulation of the model, the 2D \& 3D geometry of the model will be shown. This is then checked and energy simulation is done.It is to be seen that after modeling, the necessary doors, windows, positioning of artificial lights inside the rooms, size of doors \& windows are shown in the model. Also, the weather file uploaded initially will have all data such as sun positioning throughout the year, rainfall data, wind speed \& direction, etc. Making use of these, the software determines the actual size and shape of the windows $\&$ doors.

\section{E. Energy Simulation}

After generation of the model, energy simulation was done for calculating the energy savings of the building.By increasing the efficiency, one can greatly decrease the energy cost and pay-back period can be attained sooner. The energy simulation results for the proposed building is shown below by both methods (including \& excluding standards).

1. Without Standards \& With Electric Heaters

2. Without Standards \& With Solar Heaters

3. With ' American Society of Heating, Refrigerating and Air-Conditioning Engineers ASHRAE' Standards \& Energy Saving Techniques Excluding Solar Heaters

4. With 'ASHRAE' Standards \& Energy Saving Techniques With Solar Heaters

Also from the data analysis it was emphasised that the final value of energy usage is less when compared with the baseline energy and hence its sais that the proposed building considered in the study is fully energy competent.

\section{ENERGY SAVING RESULTS}

Energy savings for the proposed green building can be calculated from the energy simulation done using eQuest software. This software has produced the output results in a tabular form and the total energy used in 8760 hours of simulation (one year). With baseline energy level and energy level obtained after applying necessary changes, one can calculate the Energy savings by using the formula below.

Energy Savings $\quad=$ (Baseline energy level Obtained energy level) * 100 / Baseline energy level

From the IGBC reference guide, it can be taken that the points for green building for energy efficiency category are 
given based on energy savings percentage. Below is the calculation of energy savings for the proposed building. Also, only 'ASHRAE' standard simulation is used for calculating energy savings.

\section{A. Output Data From Simulation :}

Baseline Energy level is calculated without including any energy saving techniques or equipments.

1. Baseline energy level $=14560 \mathrm{kWh} /$ year

2. Obtained energy level is calculated by including any / all energy saving techniques or equipments.

3. Obtained energy level $=9960 \mathrm{kWh} /$ year

Energy Savings $(\%)=(14560-9960) * 100 / 1456=31.6$ $\%$

It can be seen that the energy savings are greater than $30 \%$ and the maximum points for this category of savings is 10 points. This is the most important design phase for designing a green building.

\section{CONCLUSION}

Green buildings may be just a decade old, but the amount of importance they represent is very high. The process for making a building green involves several processes which may seem wasteful to a simple user. But, as we consume all the resources that are available to us, the importance of this green building will keep on increasing. The main disadvantage of a green building is its initial cost. It may be decreased with correct planning and distribution of materials, labor or other necessities. This software is used to improve the design of the proposed building by using those concepts in this design. Energy analysis is the most important part of the design of a green building and it waS done using "eQuest" software.

\section{ACKNOWLEDGMENT}

The authors sincerely thanks to the Management, Principal, HoD/Civil Engineering Department of Kumaraguru College of Technology, Coimbatore for providing all the necessary supports and giving permission to use the computer lab facilities for conducting the simulation studies.

\section{REFERENCES}

1. ANSI/ASHRAE Standard 90.1-2010 - Energy Standard for Buildings except Low-Rise Residential Buildings (I-P Edition).

2. Energy Conservation Building Code (ECBC) 2009 User guide published by Bureau of Energy Efficiency.

3. LEED 2011 for India published by IGBC.

4. IGBC Green Homes (V 2.0) Abridged Reference Guide published by IGBC.

5. IGBC New Buildings rating system Abridged Reference Guide by IGBC. 